\title{
Radiation prophylaxis as primary prevention of heterotopic ossification of the knee: classification of disease and indications for treatment
}

\author{
Larry C. Daugherty $•$ Jason R. Bell • Brandon J. Fisher • \\ Neal Sankhla • Katherine Tzou • Filip Troicki • \\ Michael L. Wong • Lydia T. Komarnicky • \\ Luther W. Brady
}

Received: 2 October 2012 / Accepted: 25 October 2012 /Published online: 11 November 2012

(C) Springer-Verlag Berlin Heidelberg 2012

\begin{abstract}
Objective Heterotopic ossification (HO) of the knee joint is seen in up to $42 \%$ of patients following total knee arthroplasty (TKA). Despite this prevalence, there is a paucity of data to validate the efficacy and after effects of prophylactic radiotherapy (PRT) to the knee to prevent HO. We report retrospectively our institution's experience with 12 patients treated with PRT of the knee joint. We also present a classification scheme and review the indications for PRT following TKA. Methods Between 1999 and 2010, 112 patients were treated at our institution with PRT for prevention of HO. Of these patients, 12 underwent PRT to the knee joint and were included in our analysis. All patients were treated with one fraction of PRT to a total dose of 700 cGy. Primary end points were joint range of motion (ROM) and HO formation. ROM was evaluated as "limited" or "full" by the patient's surgeon or primary care provider at the most recent follow-up examination. The most recent radiograph was evaluated for presence of HO.

Results With a median follow-up time of 78 months (range, 1-132 months), 0/12 patients had evidence of HO on x-ray
\end{abstract}

L. C. Daugherty $(\bowtie) \cdot K$. Tzou

Department of Radiation Oncology, Mayo Clinic,

Jacksonville, FL, USA

e-mail: daugherty.larry@mayo.edu

L. C. Daugherty $\cdot$ J. R. Bell $\cdot$ N. Sankhla $\cdot$ F. Troicki •

M. L. Wong $\cdot$ L. T. Komarnicky $\cdot$ L. W. Brady

Department of Radiation Oncology, Drexel University,

Philadelphia, PA, USA

\section{B. J. Fisher}

Department of Radiation Oncology, Gamma West Cancer

Services,

Ogden, UT, USA imaging. Full ROM was documented in $11 / 12$ patients. One patient had limited ROM at the most recent follow-up due to severe osteoarthritis. No patient had impaired mobility or ROM directly attributed to fibrosis or late effects of PRT. Conclusion Based on our retrospective analysis, PRT appears to be a safe, effective treatment for prophylaxis of $\mathrm{HO}$ in the knee joint.

Keywords Heterotopic $\cdot$ Ossification $\cdot$ Knee · Radiotherapy $\cdot$ Prophylaxis

\section{Introduction}

Although heterotopic ossification (HO) is a common, wellcharacterized phenomenon in the hip joint, data regarding the classification and natural progression of $\mathrm{HO}$ in the knee joint are scarce. Given the abundance of information about the hip in the literature, patients at high risk for HO formation in the hip joint are now identified with relative ease, and prophylactic radiotherapy (PRT) or nonsteroidal antiinflammatory drugs (NSAIDs) are offered routinely. Conversely, there is a paucity of data to support PRT or NSAID prophylaxis in patients undergoing surgical manipulation of the knee joint.

Similar to HO of the hip, HO of the knee consists of idiopathic bone formation in soft-tissue structures, which can cause nerve entrapment, joint dysfunction, or ankylosis. It is most commonly observed following surgery, trauma, neurological injury, or burns [1-3]. Rare hereditary forms such as fibrodysplasia ossificans progressiva, progressive osseous heteroplasia, and Albright's hereditary osteodystrophy have also been described [4]. HO of the knee has been reported in patients with severe arthritis, hyperostosis, ankylosing 
spondylitis, infection, manipulation of the distal femur during surgery (for example, the "press-fit" surgical technique), and in patients who previously had $\mathrm{HO}$ of any joint $[1,4-6]$.

Primary prevention of $\mathrm{HO}$ has routinely been offered to high-risk patients because the incidence of $\mathrm{HO}$ following total hip arthroplasty (THA) has been reported to be as high as $50 \%[7,8]$. Similarly, HO following total knee arthroplasty (TKA) has been observed in up to $42 \%$ of patients [9-12]; however, prophylaxis for HO has only been reported as secondary prevention following surgical resection of clinically apparent HO [13] but never as primary prevention in high-risk patients. Indeed, at least one author has argued against $\mathrm{HO}$ prophylaxis in the knee joint because its clinical significance was perceived as questionable [14]. Whereas $\mathrm{HO}$ of the knee is commonly a self-limited process that spontaneously resolves in some patients, multiple studies now report significant morbidity related to knee HO, such as pain, decreased range of motion (ROM), impaired ambulation, and ankylosis of the knee joint [12, 13, 15-23].

The pattern of HO formation in the knee joint follows a distinctly different process from that observed in the hip joint. $\mathrm{HO}$ of the knee is most commonly observed initially either in the periarticular soft tissues or along the anterior edge of the distal femur. Deposits of $\mathrm{HO}$ are frequently observed in the medial aspect of the knee joint in the area known as the quadriceps expansion [13]. HO following TKA appears to depend in part on the surgical technique used, such as splitting of the quadriceps tendon and notching of the femur, which have been associated with high rates of $\mathrm{HO}[1,6]$.

Because the hip joint is the most common site of $\mathrm{HO}$, the majority of data regarding $\mathrm{HO}$ prophylaxis and treatment have been focused there. Although surgery remains the most effective salvage treatment for HO, radiation therapy (RT) and NSAIDs have proven to be effective prophylactic measures for patients at high risk of developing $\mathrm{HO}$ around the hip joint [24]. Clinicians have feared that RT prophylaxis may cause radiation-induced fibrosis and malignancy, but several studies have found that the incidence of such complications is extremely low [13, 25-30]. Furthermore, many clinicians prefer RT because of the increased risk of nonunion with the use of NSAIDs [31, 32].

Whereas the classification scheme devised by Brooker et al. [33] has become the accepted standard for HO of the hip joint, classification of $\mathrm{HO}$ in the knee joint is poorly described. Prior attempts at classification of the disease have failed to detail the full spectrum of clinical presentations and have been criticized for their limited practical utility [9-12, 34].

The only scientific data that exist on $\mathrm{HO}$ of the knee consist of retrospective studies examining its incidence after TKA [7-12] and the use of RT for secondary prophylaxis after HO excision [13]. In this retrospective analysis, we present our experience with primary prevention of $\mathrm{HO}$ in the knee joint in 12 patients who received RT for HO prophylaxis. We found no reports in the literature on use of RT as primary prophylaxis of HO rather than as secondary prevention following $\mathrm{HO}$ formation. We also propose a novel yet comprehensive classification system for $\mathrm{HO}$ of the knee and identify comprehensive risk factors that can guide the clinician in offering RT for primary prevention following TKA.

\section{Methods}

Between 1999 and 2010, 112 patients were treated prophylactically at Drexel University College of Medicine, Hahnemann University Hospital for HO. Of these patients, 91 underwent RT for HO prophylaxis in the hip joint and nine patients, in the elbow joint. We identified retrospectively 12 patients who underwent PRT for $\mathrm{HO}$ of the knee joint. Patients included eight men and four women. Median age was 46 years (range, 32-62 years). Follow-up was at the discretion of the surgeon. All patients were seen within 1 year of surgery. Median follow-up time was 78 months (range, 1-132 months). All patients had at least one highrisk feature for $\mathrm{HO}$ formation in the knee. Patient characteristics are shown in Table 1.

Simulation and treatment were performed within $72 \mathrm{~h}$ of surgery in all patients. All patients were treated with opposed anterior and posterior fields measuring a median of $10.5 \mathrm{~cm}$ wide (range, $8.5-11.5 \mathrm{~cm}$ ) $\times 12.0 \mathrm{~cm}$ long (range, $10.0-16.0 \mathrm{~cm}$ ). We made sure that our treatment fields included the quadriceps expansion and patellar tendon.

Skin-sparing technique was employed, with a minimum of a 1-cm strip of skin spared on either side of the patella to

Table 1 Patient characteristics

\begin{tabular}{lllll}
\hline Patient & Sex & $\begin{array}{l}\text { Age } \\
\text { (years) }\end{array}$ & $\begin{array}{l}\text { Knee } \\
\text { undergoing } \\
\text { RT }\end{array}$ & $\begin{array}{l}\text { Indication for RT } \\
\text { prophylaxis }\end{array}$ \\
\hline 1 & F & 32 & Left & Trauma \\
2 & M & 43 & Right & Ankylosing spondylitis \\
3 & M & 36 & Left & Trauma \\
4 & F & 58 & Right & Prior HO in hip joint \\
5 & M & 62 & Right & Severe OA \\
6 & F & 51 & Left & TKA revision, OA \\
7 & M & 49 & Left & Surgical technique \\
8 & M & 38 & Left & Trauma \\
9 & M & 34 & Right & Trauma \\
10 & F & 57 & Right & Severe OA \\
11 & M & 52 & Right & Surgical technique \\
12 & F & 33 & Left & Trauma \\
\hline
\end{tabular}

$H O$ heterotopic ossification, $O A$ osteoarthritis, $R T$ radiotherapy, TKA total knee arthoplasty 
prevent impaired lymphatic drainage. All patients were treated with one fractional dose of radiation using a highenergy linear accelerator to a total dose of $700 \mathrm{cGy}$. Dose was prescribed to midplane with equally weighted fields. Pretreatment portal films were obtained to ensure accuracy of RT delivery. Primary end points were joint ROM and HO formation. Both active and passive ROM were evaluated and documented as either "limited" or "full" ROM at the time of the most recent follow-up with either the patient's surgeon or primary care provider. All radiographs of the involved joint from the time of surgery until the most recent follow-up were evaluated for $\mathrm{HO}$ formation.

\section{Results}

With a median follow-up time of 78 months, none of our 12 patients had radiographic evidence of $\mathrm{HO}$ at any point from the time of RT administration until the most recent followup (Table 2). ROM was reported as "full" in 11 of the 12 patients. At the most recent follow-up visit, one patient reported "limited" ROM that was attributed to severe osteoarthritis (OA). None of the patients had impaired mobility or impaired ROM directly attributed to fibrosis or late effects of RT. No secondary malignancies were identified.

\section{Discussion}

Our study demonstrates that PRT is a safe and effective therapy for $\mathrm{HO}$ prevention in the knee joint. In comparison with $\mathrm{HO}$ of the hip joint, $\mathrm{HO}$ of the knee joint has been a poorly defined entity. Whereas identification of high-risk patients and indications for prophylaxis in the hip joint are widely accepted, $\mathrm{HO}$ of the knee joint remains more mysterious. Classification of the disease and indications for treatment of $\mathrm{HO}$ of the knee joint has largely been borrowed from the literature about the hip, despite the fact that each condition follows a distinct clinical course. The goal of this study was to demonstrate the safety and efficacy of RT prophylaxis as primary prevention of $\mathrm{HO}$ of the knee joint. We also sought to put forth indications for RT prophylaxis as well as a classification system for $\mathrm{HO}$ of the knee, based on a review of published literature.

Incidence of clinically significant $\mathrm{HO}$ of the knee

Heterotopic ossification is a well-documented phenomenon associated with joint surgery, traumatic fracture, spinal cord trauma, burns, and head injury [15]. Although HO is known to occur in all large joints in high-risk patients, the majority of published articles pertain only to the hip joint, in which the incidence of $\mathrm{HO}$ following THA is at least $50 \%$ [7]. Whereas many patients who develop HO in the hip joint are asymptomatic, nearly $25 \%$ of patients who develop $\mathrm{HO}$ in the hip joint will develop joint pain, decreased ROM, or even ankylosis [26].

Indications for HO prophylaxis in the hip joint are likewise well documented. In 1981, Coventry and Scanlon [27] were the first to document the effectiveness of RT as postoperative prophylaxis for $\mathrm{HO}$ in the hip joint. Subsequent investigators have also demonstrated the effectiveness of this technique [26, 28]. Equivalence of a single fraction over multiple fractions of radiation has also been demonstrated [28, 29]. Many institutions extrapolate data from the hip literature to other joints; however, there is a paucity of data to support HO prophylaxis in joints other than the hip. The use of RT for primary prevention of $\mathrm{HO}$ in the knee joint is limited to a single case report [30].
Table 2 Results of range of motion and radiographic review

$H O$ heterotopic ossification, $R T$ radiotherapy

\begin{tabular}{lllllll}
\hline Patient & Sex & $\begin{array}{l}\text { Age } \\
\text { (years) }\end{array}$ & $\begin{array}{l}\text { Knee } \\
\text { undergoing } \\
\text { RT }\end{array}$ & $\begin{array}{l}\text { Range } \\
\text { of motion }\end{array}$ & $\begin{array}{l}\text { Radiographic } \\
\text { evidence } \\
\text { of HO }\end{array}$ & $\begin{array}{l}\text { Follow- } \\
\text { up (month) }\end{array}$ \\
\hline 1 & F & 32 & Left & Full & No & 1 \\
2 & M & 43 & Right & Full & No & 18 \\
3 & M & 36 & Left & Limited & No & 96 \\
4 & F & 58 & Right & Full & No & 53 \\
5 & M & 62 & Right & Full & No & 72 \\
6 & F & 51 & Left & Full & No & 48 \\
7 & M & 49 & Left & Full & No & 132 \\
8 & M & 38 & Left & Full & No & 96 \\
9 & M & 34 & Right & Full & No & 106 \\
10 & F & 57 & Right & Full & No & 84 \\
11 & M & 52 & Right & Full & No & 94 \\
12 & F & 33 & Left knee & Full & No & 12 \\
\hline
\end{tabular}


HO is known to develop in 4 to $42 \%$ of patients following TKA [9-12]. From experience at a Japanese hospital, Toyoda et al. [14] reported an incidence of HO in $39 \%$ of patients at an average of 4 weeks postoperatively following TKA. Risk factors significant for HO formation included severe OA, press-fit fixation of the tibia during TKA, and preoperative osteophyte formation. However, despite the high incidence of $\mathrm{HO}$, examination of patients at 1 year demonstrated no effect of $\mathrm{HO}$ on range of motion. The extent of $\mathrm{HO}$ was noted to stabilize at 1 year, and $\mathrm{HO}$ even resolved spontaneously in several patients. Although the authors of this study did not examine other symptoms related to HO (for example, pain in the joint), they concluded that prophylaxis, including postoperative RT, was not recommended.

The Japanese experience is inconsistent with that of several other researchers who have reported cases of symptomatic $\mathrm{HO}$ in the knee joint. Rader et al. [12] published a large retrospective report of 615 TKA procedures performed in 558 patients. The authors reported an incidence of $\mathrm{HO}$ in $54 / 615$ patients $(9 \%)$. Four of the patients who developed HO had severe pain and limited ROM with dysfunction of the extensor apparatus. Surgical excision and administration of indomethacin were successful in alleviating symptoms in two of the four patients. The authors concluded that HO prophylaxis should be considered in high-risk patients, including those with marked hypertrophic arthrosis or marked periosteal damage during TKA (for example, press-fit surgical technique).

In a retrospective study, Fuller et al. [16] reported on 17 patients (22 knees) who developed HO of the knee following neurological injury. The patients in this study reported pain and demonstrated decreased ROM. Surgical excision of HO was used to alleviate these symptoms.

In a small case series reported by Chidel et al. [13], symptomatic $\mathrm{HO}$ of the knee was treated in five patients (sic knees). In addition to reports of pain and decreased ROM, one patient had near ankylosis of the posterior aspect of the joint with severely limited ROM.

Mitsionis et al. [35] retrospectively analyzed all cases of HO from a single institution from 1999 to 2006. During this period, 117 joints were identified with the presence of $\mathrm{HO}$. Clinically significant $\mathrm{HO}$ of the knee was reported in $20 \%$ of all joints analyzed. Surgical debulking of knee HO was performed on 23 joints, and postoperative ROM improved in $82 \%$. Patients also had improved ambulation in $57 \%$ of cases and improved sitting ability in $93 \%$ of cases.

Based on this evidence, it is clear that $\mathrm{HO}$ of the knee joint is not only common but also commonly problematic. Given the lack of comprehensive guidelines to identify at-risk patients, current practice does not involve HO prophylaxis of the knee in most patients. Instead, treatment is delayed until HO manifests itself - a dramatically different approach to HO treatment in the hip joint. Although most patients can be effectively salvaged with a combination of surgery and either postoperative RT or NSAIDs (such as indomethacin), a more prudent approach would be to prevent $\mathrm{HO}$ formation, effectively sparing patients further surgery.

Chalidis et al. [36] recently investigated the issue of early compared with late intervention of HO. Their study was designed to address whether there is a benefit in allowing HO to fully develop before offering surgical therapy. In this meta-analysis, the authors reviewed all surgical literature in an attempt to determine whether patients could be treated "too early" for $\mathrm{HO}$ formation. In their review of 255 patients across 16 studies, the authors reported no difference in functional outcomes in patients who underwent $\mathrm{HO}$ excision within 13 months of diagnosis versus 30 months of diagnosis. In each of the 16 studies examined, patients undergoing surgical treatment of $\mathrm{HO}$ were thereafter treated with either RT or NSAIDs for further HO prophylaxis. The metaanalysis suggests that PRT, whether offered early or late in the course of $\mathrm{HO}$ pathogenesis, is effective in preventing further $\mathrm{HO}$, as long as no gross disease is apparent (for example, following surgical excision of $\mathrm{HO}$ ).

Thus it makes sense to offer HO prophylaxis as early as possible -including before $\mathrm{HO}$ is even clinically apparent -in high-risk patients. This approach would spare many patients the morbidity of invasive surgery and the morbidity of potentially irreversible joint damage from ectopic bone. Such an approach has been successful in the hip joint and lends itself to investigation in other large joints, such as the knee, where HO commonly occurs.

\section{Indications for $\mathrm{HO}$ prophylaxis in the knee joint}

In Table 3, we propose indications for $\mathrm{HO}$ prophylaxis in the knee joint. Although prior publications have identified individual risk factors for $\mathrm{HO}$ of the knee following TKA [7, 9-16, 35-38], our report represents the first comprehensive attempt to offer guidelines for HO prophylaxis in the knee joint. Although our review of the literature was as complete as possible, given the relative rarity of $\mathrm{HO}$ of the knee, the sparse data may not have allowed us to identify every possible risk factor for $\mathrm{HO}$ formation in the knee joint. For example, $\mathrm{HO}$ of the knee joint has been reported following traumatic brain injury and spinal cord injury; however, further studies are needed to identify which patients among this cohort with neurological injury would benefit from prophylaxis via RT or NSAID administration.

Justification for these indications stems from a comprehensive review of the published literature pertaining to $\mathrm{HO}$ of the knee joint. Severe OA has been recognized in multiple studies as a risk factor for HO formation following TKA [9-16, 35-38]. Scott et al. [37] demonstrated that postoperative HO formation occurred in $76 \%$ of patients with $\mathrm{OA}$ and 
Table 3 Indications for RT prophylaxis for $\mathrm{HO}$ in the knee joint

$H O$ heterotopic ossification, $R T$ radiotherapy, TKA total knee arthroplasty

\author{
Preoperative diagnosis of osteoarthritis with osteophyte formation \\ Surgical manipulation of the knee following traumatic injury \\ TKA with known history of $\mathrm{HO}$ in any joint \\ TKA revision \\ Periosteal damage via surgical technique (including notching of anterior femur and cementing of tibia) \\ Elevated lumbar bone mineral density \\ Ankylosing spondylitis
}

osteophyte formation. Trauma was identified as a risk factor by Potter et al. [38], who demonstrated the presence of $\mathrm{HO}$ in $64 \%$ of patients following trauma to the joint, with severe $\mathrm{HO}$ in $34 \%$. In multiple studies, patients with a history of $\mathrm{HO}$ have shown a predilection for future $\mathrm{HO}[13,15]$.

We found no other reports in the literature of the use of RT as primary prevention of $\mathrm{HO}$ in the knee joint. Chidel et al. [13] demonstrated the effectiveness of RT in the postoperative setting following TKA. However, all patients reported in this study were offered RT as secondary prevention following excision of preexisting $\mathrm{HO}$ in the knee joint. Seventeen percent of the patients reported in Chidel's study had persistently impaired ROM, lending support to the idea of primary prevention over secondary prevention of $\mathrm{HO}$. It stands to reason that sparing patient's surgical excision as salvage, which is not always effective, would be an attractive option. Prevention of HO could drastically improve quality of life in patients who, without effective prophylaxis, would develop symptomatic $\mathrm{HO}$ with pain and impaired ROM. Patients selected for RT prophylaxis in our study were deemed high risk owing to the presence of severe OA and a history of $\mathrm{HO}$ formation, trauma, and the surgical technique used.

Classification of $\mathrm{HO}$ of the knee joint

In addition to unclear indications for HO prophylaxis, overall classification of $\mathrm{HO}$ of the knee joint has not been widely adopted as has classification of HO of the hip joint. Since
1973, the Brooker classification of HO of the hip joint [33] has been widely accepted and adopted in documenting both location and severity of $\mathrm{HO}$ within the hip joint. However, there is no uniformly accepted classification system for $\mathrm{HO}$ of the knee joint. Two authors have introduced grading systems based on observational studies of HO development in small samples of patients (Table 4) [9, 11]. However, the so-called Figgie and Harwin grading systems have been criticized as inadequate in classifying all patients with $\mathrm{HO}$ of the knee. In attempting to apply either or both of these schemes to patients for whom RT prophylaxis was being considered, one author noted that "neither of these systems was adequate in evaluating all of [his] patients" [13].

For a classification system to be useful and recognized, it must be a valuable tool for both the radiotherapist and the surgeon. We present a model of $\mathrm{HO}$ classification specific to the knee joint in Table 5. Figure 1 represents an illustrated version of the classification system.

Similar to the Brooker classification system, we outline classes from 0 to 4 with a grade of " 0 " representing no evidence of $\mathrm{HO}$ and a grade of "4" representing complete ankylosis of the knee joint due to HO. Each class is further subdivided into "A," for no symptoms related to HO, or "B," for any patient with symptomatic $\mathrm{HO}$ of the knee (for example, pain or limited ROM).

Classes 1-3 of our system were derived from a thorough review of the literature in an attempt to identify all known prognostic features of the disease. We emphasized function

Table 4 Comparison of Figgie and Harwin classification schemes for heterotopic ossification of the knee joint

\begin{tabular}{|c|c|c|c|}
\hline $\begin{array}{l}\text { Figgie } \\
\text { grade }\end{array}$ & Description & $\begin{array}{l}\text { Harwin } \\
\text { grade }\end{array}$ & Description \\
\hline 0 & No evidence of $\mathrm{HO}$ & 0 & No evidence of $\mathrm{HO}$ \\
\hline I & $\begin{array}{l}\text { Progressive } \mathrm{HO} \text { in at least } 1 \text { compartment } \\
\text { of the knee, without spur formation }\end{array}$ & I & $\begin{array}{l}\text { Sessile HO attached to the periosteum of the anterior femur, limited to } \\
\text { suprapatellar pouch }\end{array}$ \\
\hline II & $\begin{array}{l}\text { Progressive } \mathrm{HO} \text { in at least } 1 \text { compartment } \\
\text { of the knee, with spur formation }(>1 \mathrm{~mm})\end{array}$ & II & Amorphous or globular HO pattern limited to the quadriceps expansion \\
\hline \multirow[t]{2}{*}{ III } & \multirow[t]{2}{*}{ Complete bony ankylosis } & IIIa & $\begin{array}{l}\text { Combination of sessile and globular pattern, involvement of }<75 \% \text { of } \\
\text { the height of the soft tissues on lateral radiograph }\end{array}$ \\
\hline & & IIIb & $\begin{array}{l}\text { Combination of grades } 1 \text { and } 2 \text { with involvement of }>75 \% \text { of the height } \\
\text { of the soft tissues on lateral radiograph }\end{array}$ \\
\hline
\end{tabular}

$H O$ heterotopic ossification 
Table 5 Daugherty/Bell classification of $\mathrm{HO}$ of the knee

0 No evidence of $\mathrm{HO}$

1 Bone islands in periarticular soft tissue (no involvement of femur, patella, or tibia) or $\mathrm{HO}$ within quadriceps expansion measuring $<1 \mathrm{~cm}$

2 Spur formation measuring $<5 \mathrm{~cm}$ that involves the femur, patella, or tibia; if more than one bone demonstrates HO, separation of HO spurs measure $>1 \mathrm{~cm}$ or $\mathrm{HO}$ within quadriceps expansion measuring $\geq 1 \mathrm{~cm}$ but $<3 \mathrm{~cm}$

3 Spur formation $>5 \mathrm{~cm}$ involving femur, patella, or tibia; if more than one bone demonstrates $\mathrm{HO}$, separation of $\mathrm{HO}$ spurs measure $<1 \mathrm{~cm}$ or $\mathrm{HO}$ within quadriceps expansion measuring $\geq 3 \mathrm{~cm}$

4 Extensive $\mathrm{HO}$ of the knee causing ankylosis

$\mathrm{HO}$ heterotopic ossification

over form because, in tailoring a treatment approach, the location of $\mathrm{HO}$ is not nearly as important as the symptoms of $\mathrm{HO}$ to either the surgeon or the radiotherapist.

In keeping with this philosophy, Daugherty/Bell class 1 $\mathrm{HO}$ of the knee represents the presence of $\mathrm{HO}$ that is least likely to cause the patient any symptoms. It is well documented that $\mathrm{HO}$ of the knee commonly arises in the area of the quadriceps expansion. Early (or clinically insignificant) $\mathrm{HO}$ has also been documented in the periarticular knee. Many of the patients with this condition can likely be spared surgical intervention in favor of observation, because many authors have reported stability in the growth of this type of $\mathrm{HO}$ at 1 year or even spontaneous resolution. Our class $1 \mathrm{~B}$ category stratifies the rare patient with patchy $\mathrm{HO}$ of the periarticular knee that causes symptoms. Surgical intervention, followed by radiation prophylaxis, seems prudent in this cohort.
Daugherty/Bell classes 2 and 3 represent $\mathrm{HO}$ that is more likely to be clinically significant. In class $2, \mathrm{HO}$ begins to involve the major bones of the knee joint with spur formation limited to a size of $5 \mathrm{~cm}$. The size cutoff of $5 \mathrm{~cm}$ was selected because of the data presented by Furia and Pellegrini [15], who identified this size criterion as most likely to affect ROM of the joint. If $\mathrm{HO}$ involves more than one bone in the knee joint, a gap of $>1$ or $<1 \mathrm{~cm}$ distinguishes class 2 from class 3 and was incorporated from the Brooker system for the hip [33]. HO class 2 may be observed in select patients with complete ROM and no reported pain. Patients with class 3 HO would likely always benefit from surgical excision followed by RT prophylaxis. Certainly patients in either cohort with a subclass "B" assignment (symptomatic) would benefit from treatment. All patients with class $4 \mathrm{HO}$ require treatment to alleviate ankylosis.
Fig. $1 \mathrm{X}$ classification system for $\mathrm{HO}$ of the knee joint. a Grade $1 \mathrm{HO}$; b grade $2 \mathrm{HO}$; c grade $3 \mathrm{HO}$; d grade $4 \mathrm{HO}$. See Table 5 for detailed descriptions of respective grades

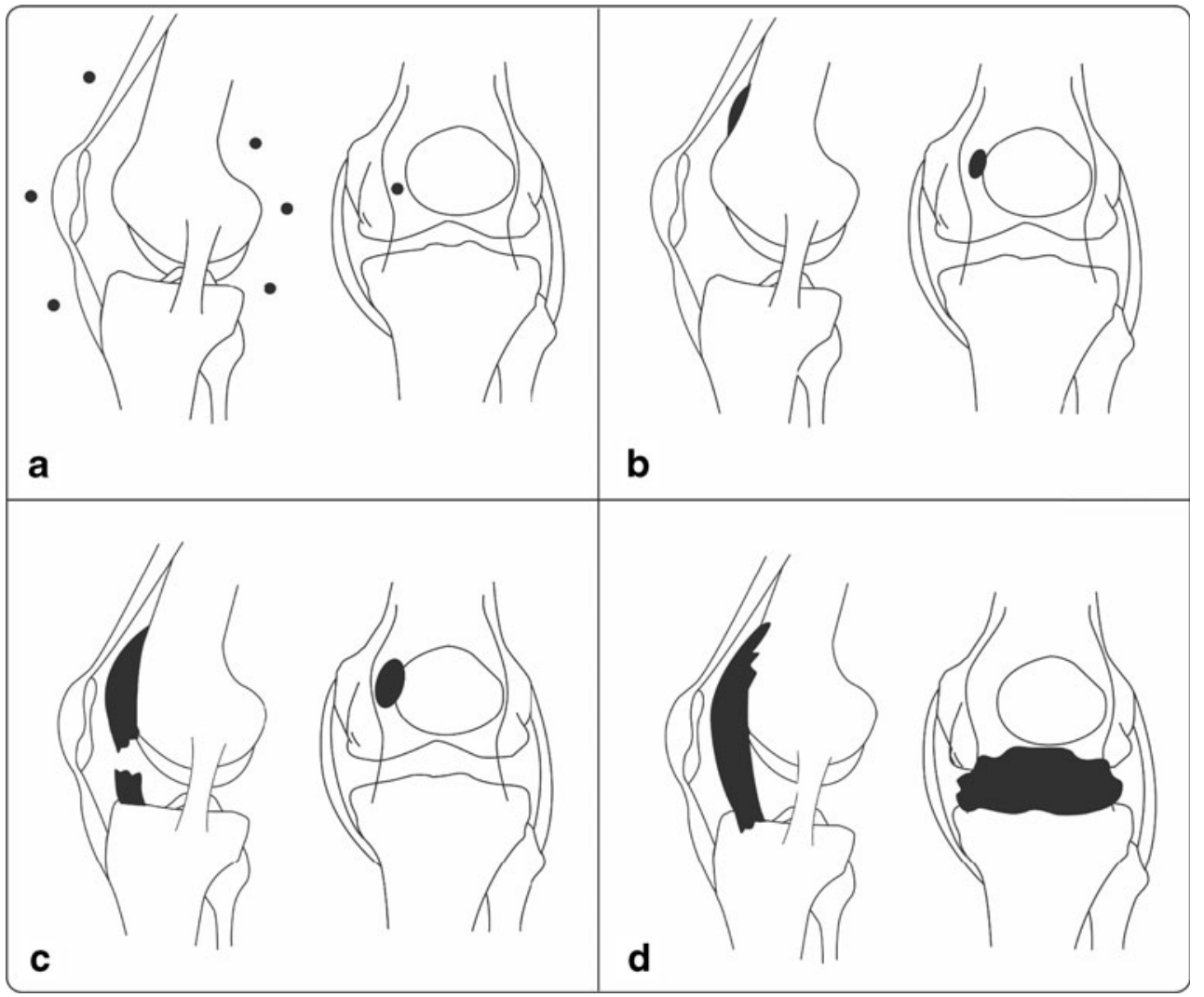


In all patients, prophylaxis of $\mathrm{HO}$ would be preferable to salvage treatment after development of symptomatic $\mathrm{HO}$ in the knee joint. However, some physicians are leery of RT prophylaxis because they are concerned about the side effects of RT, primarily fibrosis and secondary malignancy. In our series of 12 patients, the largest published series to date for RT prophylaxis in the knee joint, no patient developed limited ROM attributable to RT. In the only other reported series of RT for HO prevention, Chidel et al. demonstrated similar results in six patients and reported no clinically significant fibrosis. Although the risk of radiationinduced fibrosis is certainly not zero after a single dose of 700 to $800 \mathrm{cGy}$, the preceding data corroborate the reported fibrosis dose threshold of 10 to 20 Gy for single-fraction treatment and >50 Gy for fractionated RT [39].

Even more concerning than fibrosis would be the development of a secondary malignancy. Radiation-induced malignancy is a rare occurrence, but there is no threshold dose below which there is no risk. In our study, no malignant tumors were reported to develop within the treatment portal. Our data are consistent with those of the Memorial-Sloan Kettering Cancer Center, which has reported no cases of radiation-associated tumors with doses $<30$ Gy [30].

\section{Conclusion}

Radiotherapy delivered in a single fraction of external beam treatment has been proven effective following THA in highrisk patients. Many clinicians extrapolate this experience to non-hip joints, despite limited published clinical experience. $\mathrm{HO}$ of the knee is a separate and distinct entity, which has been shown to follow a clinical course different from that of $\mathrm{HO}$ of the hip. Accordingly, $\mathrm{HO}$ in non-hip joints, including the knee, merits distinct indications for RT prophylaxis and a distinct classification system. In our series of 12 patients, RT prophylaxis was shown to be safe and effective in preventing $\mathrm{HO}$ formation in high-risk patients.

Acknowledgments This manuscript was presented in poster form at the 2010 ASTRO Annual Meeting in San Diego, California. There was no grant or other financial support of this study.

Conflict of interest The authors declare that they have no conflicts of interest.

\section{References}

1. Dalury DF, Jiranek WA (2004) The incidence of heterotopic ossification after total knee arthroplasty. J Arthroplasty 19(4):447-452

2. Ahrengart L (1991) Periarticular heterotopic ossification after total hip arthroplasty - risk factors and consequences. Clin Orthop 263:49-58
3. Ritter MA, Vaughan RB (1977) Ectopic ossification after total hip arthroplasty. Predisposing factors, frequency, and effect on results. J Bone Joint Surg Am 59(3):345-351

4. Shehab D, Elgazzar AH, Collier BD (2002) Heterotopic ossification. J Nucl Med 43(3):346-353

5. Vanden Bossche L, Vanderstraeten G (2005) Heterotopic ossification: a review. J Rehabil Med 37(3):129-136

6. Atamaz F, Aydoğdu S, Hepgüler S, Sur H (2006) Heterotopic ossification after total knee arthroplasty [in Turkish]. Acta Orthop Traumatol Turc 40(3):202-206

7. Naraghi FF, DeCoster TA, Moneim MS, Miller RA, Rivero D (1996) Heterotopic ossification. Orthopedics 19(2):145-151

8. Ayers DC, Evarts CM, Parkinson JR (1986) The prevention of heterotopic ossification in high-risk patients by low-dose radiation therapy after total hip arthroplasty. J Bone Joint Surg Am 68 (9):1423-1430

9. Figgie HE III, Goldberg VM, Heiple KG, Moller HS III (1986) The incidence and significance of heterotopic ossification following total knee arthroplasty. Adv Orthop Surg 10:12-17

10. Lovelock JE, Griffiths JH, Silverstein AM, Anson PS (1984) Complications of total knee replacement. AJR Am J Roentgenol 142(5):985-992

11. Harwin SF, Stein AJ, Stern RE, Kulick RG (1993) Heterotopic ossification following primary total knee arthroplasty. J Arthroplasty 8(2):113-116

12. Rader CP, Barthel T, Haase M, Scheidler M, Eulert J (1997) Heterotopic ossification after total knee arthroplasty. 54/615 cases after 1-6 years' follow-up. Acta Orthop Scand 68(1):46-50

13. Chidel MA, Suh JH, Matejczyk MB (2001) Radiation prophylaxis for heterotopic ossification of the knee. J Arthroplasty 16(1):1-6

14. Toyoda T, Matsumoto H, Tsuji T, Kinouchi J, Fujikawa K (2003) Heterotopic ossification after total knee arthroplasty. J Arthroplasty 18(6):760-764

15. Furia JP, Pellegrini VD Jr (1995) Heterotopic ossification following primary total knee arthroplasty. J Arthroplasty 10 (4):413-419

16. Fuller DA, Mark A, Keenan MA (2005) Excision of heterotopic ossification from the knee: a functional outcome study. Clin Orthop Relat Res 438:197-203

17. Sterner T, Saxler G, Barden B (2005) Limited range of motion caused by heterotopic ossifications in primary total knee arthroplasty: a retrospective study of 27/191 cases. Arch Orthop Trauma Surg 125(3): 188-192

18. Barrack RL, Brumfield CS, Rorabeck CH, Cleland D, Myers L (2002) Heterotopic ossification after revision total knee arthroplasty. Clin Orthop Relat Res 404:208-213

19. Hasegawa M, Ohashi T, Uchida A (2002) Heterotopic ossification around distal femur after total knee arthroplasty. Arch Orthop Trauma Surg 122(5):274-278

20. Maloney WJ, Schurman DJ (1992) The effects of implant design on range of motion after total knee arthroplasty. Total condylar versus posterior stabilized total condylar designs. Clin Orthop Rel Res 278:147-152

21. Austin KS, Silisky JM (1995) Symptomatic heterotopic ossification following total knee arthroplasty. J Arthroplasty 10(5): 695-698

22. Pham J, Kumar R (1997) Heterotopic ossification after total knee arthroplasty. Am J Orthop 26(2):141-143

23. Baron M, Stern J, Lander P (1983) Heterotopic ossification heralded by a knee effusion. J Rheumatol 10(6):961-964

24. Chao EK, Chen AC, Lee MS, Ueng SW (2002) Surgical approaches for nonneurogenic elbow heterotopic ossification with ulnar neuropathy. J Trauma 53(5):928-933

25. Lo TC, Pfeifer BA, Smiley PM, Gumley GJ (1996) Case report: radiation prevention of heterotopic ossification after 
bone and joint surgery in sites other than hips. Br J Radiol 69 (823):673-677

26. Knelles D, Barthel T, Karrer A, Kraus U, Eulert J, Kölbl O (1997) Prevention of heterotopic ossification after total hip replacement. A prospective, randomised study using acetylsalicylic acid, indomethacin and fractional or single-dose irradiation. J Bone Joint Surg Br 79(4):596-602

27. Coventry MB, Scanlon PW (1981) The use of radiation to discourage ectopic bone: a nine-year study in surgery about the hip. J Bone Joint Surg Am 63(2):201-208

28. Seegenschmiedt MH, Keilholz L, Martus P, mann A, Wölfel R, Henning F, Sauer R (1997) Prevention of heterotopic ossification about the hip: final results of two randomized trials in 410 patients using either preoperative or postoperative radiation therapy. Int J Radiat Oncol Biol Phys 39(1):161-171

29. Konski A, Pellegrini V, Poulter C, DeVanny J, Rosier R, Evarts CM, Henzler M, Rubin P (1990) Randomized trial comparing single dose versus fractionated irradiation for prevention of heterotopic bone: a preliminary report. Int J Radiat Oncol Biol Phys 18(5):1139-1142

30. Kim JH, Chu FC, Woodard HQ, Melamed MR, Huvos A, Cantin J (1978) Radiation-induced soft-tissue and bone sarcoma. Radiology 129(2):501-508

31. Pakos EE, Ioannidis JP (2004) Radiotherapy vs. nonsteroidal antiinflammatory drugs for the prevention of heterotopic ossification after major hip procedures: a meta-analysis of randomized trials. Int $\mathrm{J}$ Radiat Oncol Biol Phys 60(3):888-895
32. Burd TA, Hughes MS, Anglen JO (2003) Heterotopic ossification prophylaxis with indomethacin increases the risk of long-bone nonunion. J Bone Joint Surg Br 85(5):700-705

33. Brooker AF, Bowerman JW, Robinson RA, Riley LH Jr (1973) Ectopic ossification following total hip replacement. Incidence and a method of classification. J Bone Joint Surg Am 55(8):1629-1632

34. Mills WJ, Tejwani N (2003) Heterotopic ossification after knee dislocation: the predictive value of the injury severity score. J Orthop Trauma 17(5):338-345

35. Mitsionis GI, Lykissas MG, Kalos N, Paschos N, Beris AE, Georgoulis AD, Xenakis TA (2009) Functional outcome after excision for heterotopic ossification about the knee in ICU patients. Int Orthop 33(6):1619-1625

36. Chalidis B, Stengel D, Giannoudis PV (2007) Early excision and late excision of heterotopic ossification after traumatic brain injury are equivalent: a systematic review of the literature. J Neurotrauma 24 (11):1675-1686

37. Scott WN, Rubinstein M, Scuderi G (1988) Results after knee replacement with a posterior cruciate-substituting prosthesis. J Bone Joint Surg Am 70(8):1163-1173

38. Potter BK, Burns TC, Lacap AP, Granville RR, Gajewski DA (2007) Heterotopic ossification following traumatic and combat-related amputations. Prevalence, risk factors and preliminary results of excision. J Bone Joint Surg Am 89(3):476-486

39. Gillette EL, Mahler PA, Powers BE, Gillette SM, Vujaskovic Z (1995) Late radiation injury to muscle and peripheral nerves. Int $\mathrm{J}$ Radiat Oncol Biol Phys 31(5):1309-1318 